\title{
Outcome of Total Parathyroidectomy and Autotransplantation as Treatment of Secondary and Tertiary Hyperparathyroidism in Children and Adults
}

\author{
A. J. Kievit • J. G. M. Tinnemans • M. M. Idu • \\ J. W. Groothoff $\cdot$ S. Surachno $\cdot$ D. C. Aronson
}

Published online: 10 February 2010

(C) The Author(s) 2010. This article is published with open access at Springerlink.com

\begin{abstract}
Background Treatment safety and effectiveness of total parathyroidectomy and autotransplantation for secondary and tertiary hyperparathyroidism have been extensively proven in adults; the evidence for children, however, is scarce. Children and adolescents cannot simply be seen as young adults in the case of chronic kidney disease and hyperparathyroidism. The aim of this retrospective study was therefore, to evaluate whether parathyroidectomy with forearm autograft is as effective and safe in children and adolescents as in adults.

Methods A group of 64 adults and 8 children and adolescents treated for secondary or tertiary hyperparathyroidism
\end{abstract}

\section{A. J. Kievit · D. C. Aronson}

Pediatric Surgical Center of Amsterdam, Emma Children's

Hospital, Academic Medical Center, PO Box 22660,

Meibergdreef 9, 1100 DD Amsterdam, The Netherlands

J. G. M. Tinnemans - M. M. Idu

Department of Surgery, Academic Medical Center,

PO Box 22660, Meibergdreef 9, 1100 DD Amsterdam,

The Netherlands

J. W. Groothoff

Department of Pediatrics, Division of Pediatric Nephrology, Emma Children's Hospital, Academic Medical Center,

PO Box 22660, 1100 DD Amsterdam, The Netherlands

\section{S. Surachno}

Renal Transplant Unit, Academic Medical Center,

PO Box 22660, Meibergdreef 9, 1100 DD Amsterdam,

The Netherlands

\section{C. Aronson ( $\square)$}

Department of Surgery, Division of Pediatric Surgery (816), Radboud University Nijmegen Medical Center, Postbus 9101, 6500 HB Nijmegen, The Netherlands

e-mail: d.aronson@chir.umcn.nl were retrieved from our database. The outcomes were compared on patient demographics, operation results, and blood parameters consisting of parathyroid hormone (PTH) and calcium levels. Our results were compared with all currently available articles on parathyroidectomy in children with secondary or tertiary hyperparathyroidism $(n=11)$.

Results For adults, preoperative mean serum calcium was $2.67 \pm 0.29 \mathrm{mmol} / \mathrm{l}$ and mean parathyroid hormone $(\mathrm{PTH})$ level was $120 \pm 86 \mathrm{pmol} / \mathrm{l}$. For children, preoperative mean serum calcium was $2.62 \pm 0.20 \mathrm{mmol} / \mathrm{l}$ and mean parathyroid hormone (PTH) level was $80 \pm 38 \mathrm{pmol} / \mathrm{l}$. Postoperative calcium and parathyroid hormone levels for adults dropped to $2.39 \pm 0.23 \mathrm{mmol} / \mathrm{l}$ and $30 \pm 53 \mathrm{pmol} /$ 1 , respectively. Postoperative calcium and parathyroid hormone levels for children dropped to $2.41 \pm 0.16 \mathrm{mmol} /$ 1 and $26 \pm 33$ pmol/l, respectively. The effectiveness of parathyroidectomy with autotransplantation was $75 \%$ in children and $72 \%$ in adults. Thus, effectiveness did not differ significantly between children and adults.

Conclusions Combining the results of our own study with a literature review on pediatric parathyroidectomy, we conclude that parathyroidectomy and forearm autograft is as effective a treatment for secondary and tertiary hyperparathyroidism in children and adolescents as it is in adults.

\section{Introduction}

The incidence of renal insufficiency in adults is only $40-70$ per million, and in children it is even lower, at $0.5-5$ per million $[1,2]$. A significant proportion of patients with renal insufficiency develop secondary and eventually tertiary hyperparathyroidism. If left untreated, hyperparathyroidism can lead to symptoms of hypercalcemia, renal 
complications, and bone disease connected to hyperparathyroidism, which is characterized by high turnover and remodeling rates leading to osteoporosis and increased fracture risk. If hyperparathyroidism becomes clinically significant, or if a patient undergoes work-up for renal transplantation, parathyroidectomy is usually performed, either subtotal, or total in combination with autotransplantation, to prevent aparathyroidism [3-10].

The Amsterdam Academic Medical Centre and the Emma Children's Hospital (AMC) form a care unit for secondary or tertiary hyperparathyroidism to which children, adolescents, and adults with this disease are referred for treatment on a regular basis. For such a care unit, it is important to assess provided care to assure high quality. Few articles have reported on surgical treatment for secondary or tertiary hyperparathyroidism in children and adolescents, and none have compared outcomes in children and adolescents with outcomes in adults. Children and adolescents cannot simply be seen as young adults if they suffer from chronic renal disease and hyperparathyroidism. The resulting growth retardation and the potentially rapid onset of renal osteodystrophy (ROD) in children are different from ROD in adults. If left untreated during the critical phases of skeletal growth, ROD can result in bone deformities and a disturbed growth pattern [11].

The aim of the present study was therefore to evaluate if parathyroidectomy with forearm autograft is as effective and safe in pediatric and adolescent patients as in adult patients and, therefore, if treating them the same way is justifiable even though there are differences in the effect of the disease. More specific study questions were (1) is secondary or tertiary hyperparathyroidism treated effectively by this surgical treatment, in children and adolescents as well as in adults? (2) Is parathyroid function adequate after surgery and, if so, could this benefit be ascribed to the autotransplanted tissue in children and adolescents as well as in adults? (3) Which factors are predictors for an effective surgical treatment and for the conservation of sufficient parathyroid function and, again, do these factors differ between children and adolescents on the one hand and adults on the other?

\section{Patients and methods}

A list of all patients who had been treated by complete removal of the parathyroid glands and autotransplantation to the forearm (PTx) from 1988 to 2006 was retrieved from the operation administration of the Amsterdam Medical Centre. Indications for surgical treatment of secondary hyperparathyroidism are severe hypercalcemia $(>3 \mathrm{mmol} /$ 1), progressive and incapacitating hyperparathyroid bone disease, and severe pruritis. For tertiary hyperparathyroidism, the indications are consistently high parathyroid hormone levels ( $>35 \mathrm{pmol} / \mathrm{l})$ and calcium levels $(>2.60 \mathrm{mmol} /$ 1) and hypercalciuria after renal organ transplantation.

Data on these patients were collected from patient files, operative reports, and office notes, mainly from the Amsterdam Medical Centre digital hospital information system. Data collected consisted of patient demographics, record of renal transplant in the patient's history and/or type of dialysis at the time of operation, details of the parathyroidectomy, complications, including all adverse outcomes that occurred after the operation and required treatment by any means, and any reoperations necessary for persistent hypercalcemia.

The adults had a mean age of 48.6 years \pm 11.3 with a minimum age of 23.1 years and a maximum of 72.4 years.

Table 1 Group specifics

\begin{tabular}{llllc}
\hline & & Adults & Children & Total \\
& & $N(\%)$ & $N(\%)$ & $N(\%)$ \\
\hline Sex & Male & $28(44 \%)$ & $4(50 \%)$ & $32(44 \%)$ \\
& Female & $36(56 \%)$ & $4(50 \%)$ & $40(56 \%)$ \\
Kidney transplanted before & Yes & $26(41 \%)$ & $3(38 \%)$ & $29(40 \%)$ \\
parathyroidectomy & No & $38(59 \%)$ & $5(62 \%)$ & $43(60 \%)$ \\
Type of hyperparathyroidism & Secondary & $47(73 \%)$ & $5(62 \%)$ & $53(72 \%)$ \\
at the time of parathyroidectomy & Tertiary & $17(27 \%)$ & $3(38 \%)$ & $20(28 \%)$ \\
Treated by dialysis & Yes & $37(58 \%)$ & $5(62 \%)$ & $42(58 \%)$ \\
& No & $24(37 \%)$ & $3(38 \%)$ & $27(38 \%)$ \\
& Missing & $3(5 \%)$ & $0(0 \%)$ & $3(4 \%)$ \\
Type of dialysis & Hemodialysis & $22(34 \%)$ & $3(38 \%)$ & $25(35 \%)$ \\
& Peritoneal dialysis & $15(23 \%)$ & $2(25 \%)$ & $17(24 \%)$ \\
& None & $24(38 \%)$ & $3(38 \%)$ & $27(37 \%)$ \\
& Missing & $3(5 \%)$ & $0(0 \%)$ & $3(4 \%)$ \\
Total & & $64(89 \%)$ & $8(11 \%)$ & $72(100 \%)$ \\
\hline
\end{tabular}


The children had a mean age of 13.8 years \pm 3.2 with a minimum of 8.8 years and a maximum of 17.8 years. Further patient characteristics are shown in Table 1.

\section{Surgery}

Total parathyroidectomy with forearm autograft is the standard of care for these patients at the AMC, and it was performed in all 81 patients. Cervical thymectomy was only performed if the surgeon deemed it necessary. Autotransplantation was performed by implanting half a parathyroid gland cut into, on average, fifteen $1 \mathrm{~mm}^{3}$ pieces into three pockets in the brachioradial muscle of the forearm.

\section{Assessment of outcome}

Parathyroid autotransplant function was assessed by comparing preoperative and postoperative serum parathyroid hormone (PTH in pmol/l) and calcium (calcium in $\mathrm{mmol} / \mathrm{l}$ ) levels. When uncertainty existed about parathyroid transplant function, a MIBI scan of the forearm was performed. Information on preoperative and postoperative parathyroid function was collected as follows: Preoperatively the last three sets of concurrent PTH and calcium values were measured within, at most, 1 year before operation, preferably close to the operation date. Postoperatively, parathyroid autotransplant function was assessed from 1 month postoperatively, to allow for autotransplant in growth and to prevent confusion about parathyroid (dys)function resulting from the high dosages of calcium that many patients received. Up to five sets of concurrent PTH and calcium values were retrieved between 1 and 12 months after the operation, as close as possible to $1,3,6,9$, and 12 months postoperatively. If a renal transplant was performed inside the follow-up period, that fact was noted.

\section{Definitions and criteria}

The following criteria were used for this study: We considered patients as suffering from secondary hyperparathyroidism if they had no functioning kidney transplant at the time of parathyroidectomy. Patients who had a functioning kidney transplant at the time of parathyroidectomy and during 1 year of follow-up were considered suffering from tertiary hyperparathyroidism.

Patients were considered effectively treated if the average PTH value, calculated from the up to five samples obtained over the 11-month postoperative period, was $25 \mathrm{pmol} / \mathrm{l}$ or less. Patients who were not effectively treated were considered for reoperation. In addition, effectiveness was assessed at stricter thresholds for serum PTH levels of 16 and $8 \mathrm{pmol} / \mathrm{l}$.
Patients were considered aparathyroid if they had an average PTH value of $1 \mathrm{pmol} / \mathrm{l}$ or less. We assumed that aparathyroidism had been prevented by successful autotransplantation if four or more parathyroid glands had been identified in the neck, all glands were completely resected, a portion of one parathyroid gland had been autotransplanted at the time of operation, and the patient had an average PTH value of $1 \mathrm{pmol} / \mathrm{l}$ or more.

We assessed the following factors for their ability to predict effective surgical treatment: age, preoperative $\mathrm{PTH}$, preoperative calcium, number of identified and resected parathyroid glands, and renal transplant status at operation. As predictors for prevention of aparathyroidism by autotransplantation, we assessed patient age and method of autotransplantation.

\section{Results}

The patient group consisted of 81 patients, 73 adults and 8 children and adolescents. Nine patients, all adults, were excluded from the study because they either had preoperative or postoperative blood values but not both. Therefore an evaluation of effectiveness was not possible for these patients. Our patient group therefore included 64 adults and 8 children. Of the adults, 47 patients had no functioning kidney transplant at the time of parathyroidectomy and were classified as suffering from secondary hyperparathyroidism. Six of these patients received a kidney transplant within the 1 year follow-up period. Seventeen adult patients had a functioning kidney transplant at the time of parathyroidectomy and during the 1 year follow-up period and were classified as suffering from tertiary hyperparathyroidism. According to the same criteria, 3 children suffered from secondary hyperparathyroidism and 5 from tertiary hyperparathyroidism at the time of parathyroidectomy. None of the children received a kidney transplant during the 1 year follow-up period.

\section{Operation details and results}

Operations were carried out by 9 different surgeons. The surgeon either performing the operation or supervising an assistant surgeon had ample experience with this type of surgery. Average surgery time for adults was $3: 55 \mathrm{~h} \pm 1: 00$ and for children $3: 21 \mathrm{~h} \pm 0: 49$. Further operation details are shown in Table 2.

\section{Perioperative complications}

Three weeks postoperatively, one girl had convulsions during hemodialysis due to hypocalcemia. She was admitted to the intensive care unit of the University 
Table 2 Operative details

\begin{tabular}{|c|c|c|c|c|}
\hline & & $\begin{array}{l}\text { Adults } \\
N(\%)\end{array}$ & $\begin{array}{l}\text { Children } \\
N(\%)\end{array}$ & $\begin{array}{l}\text { Total } \\
N(\%)\end{array}$ \\
\hline \multirow[t]{5}{*}{ Number of glands found } & One & $0(0)$ & $0(0)$ & $0(0)$ \\
\hline & Two & $1(2)$ & $0(0)$ & $1(2)$ \\
\hline & Three & $10(15)$ & $1(12)$ & $11(15)$ \\
\hline & Four & $48(75)$ & $7(88)$ & $55(76)$ \\
\hline & Five & $5(8)$ & $0(0)$ & $5(7)$ \\
\hline \multirow[t]{2}{*}{ Complications other than recurrent nerve damage } & Yes & $2(3)$ & $1(12)$ & $3(4)$ \\
\hline & No & $62(97)$ & $7(88)$ & $69(96)$ \\
\hline \multirow[t]{5}{*}{ Recurrent nerve damage } & Yes & $2(3)$ & $0(0)$ & $2(3)$ \\
\hline & No & $55(86)$ & $7(88)$ & $62(86)$ \\
\hline & Probably not, not identified & $2(3)$ & $0(0)$ & $2(3)$ \\
\hline & $\begin{array}{l}\text { No damage left side, } \\
\text { right not identified }\end{array}$ & $1(2)$ & $0(0)$ & $1(1)$ \\
\hline & Missing & $4(6)$ & $1(12)$ & $5(7)$ \\
\hline \multirow{2}{*}{$\begin{array}{l}\text { Effectively treated for the hyperparathyroidism } \\
\text { (parathyroid hormone dropped below } 25 \text { pmol/l) }\end{array}$} & Yes & $46(72)$ & $6(75)$ & $52(72)$ \\
\hline & No & $18(28)$ & $2(25)$ & $20(28)$ \\
\hline \multirow{2}{*}{$\begin{array}{l}\text { Aparathyroidism as a result of parathyroidectomy } \\
\text { (parathyroid hormone dropped below } 1 \text { pmol/l) }\end{array}$} & Yes & 7 (11) & $0(0)$ & $7(10)$ \\
\hline & No & 57 (89) & $8(100)$ & $65(90)$ \\
\hline \multirow{2}{*}{$\begin{array}{l}\text { Aparathyroidism prevented by auto-transplantation } \\
\text { (parathyroid hormone of } 1 \mathrm{pmol} / \mathrm{l} \text { or more, four or } \\
\text { more glands removed completely and autotransplantation } \\
\text { performed) }\end{array}$} & Yes & 47 (73) & $7(88)$ & $54(75)$ \\
\hline & No & 17 (27) & $1(12)$ & $18(25)$ \\
\hline Total & & 64 & 8 & 72 \\
\hline
\end{tabular}

Medical Centre Groningen and intubated the same day. There she was treated with intravenous Etalpha $1 \mu \mathrm{g}$ and calcium carbonate 3 times daily $1,000 \mathrm{mg}$, to which she responded well. A computerize tomography (CT)-scan of the brain was performed and showed no abnormalities. The patient could be extubated on the same day, and the following day she was transferred to the children's intensive care unit of the Amsterdam Medical Centre for monitoring while restarting hemodialysis. Calcium levels were checked at 1 and $3 \mathrm{~h}$ after dialysis, at which points the ionized calcium levels were 1.17 and $1.18 \mathrm{mmol} / \mathrm{l}$. No further problems occurred.

One adult patient had a postoperative bleed and a streptococcus infection, and one adult patient had postoperative pneumonia with atrial fibrillation.
Laboratory values perioperatively

Table 3 shows the PTH values and Table 4 shows the calcium values for children and adults. Figure $1 \mathrm{a}$ and $\mathrm{b}$ shows the effect of total parathyroidectomy and autotransplantation on PTH and calcium levels in children and Fig. $2 \mathrm{a}$ and $\mathrm{b}$ shows the effect in adults.

\section{Effectiveness}

In 6 children and 46 adults (nearly three-quarters of all patients), hyperparathyroidism was treated effectively, whereas in 2 children and 18 adults (one quarter), it was not.

From the two children who had PTH values higher than $25 \mathrm{pmol} / \mathrm{l}$, one underwent reoperation, which led to PTH
Table 3 Parathyroid hormone levels (in pmol/l) before and after parathyroidectomy in adults and children

\begin{tabular}{|c|c|c|c|c|}
\hline & \multicolumn{2}{|c|}{ Before parathyroidectomy } & \multicolumn{2}{|c|}{ After parathyroidectomy } \\
\hline & Adults & Children & Adults & Children \\
\hline Mean & 120 & 80 & 30 & 26 \\
\hline Standard deviation & 86 & 38 & 53 & 33 \\
\hline Median & 106 & 83 & 8 & 9 \\
\hline Maximum & 456 & 147 & 258 & 91 \\
\hline Minimum & 8 & 24 & 0 & 3 \\
\hline $\mathrm{N}$ & 64 & 8 & 64 & 8 \\
\hline
\end{tabular}


Table 4 Calcium levels $(\mathrm{mmol} / \mathrm{l})$ before and after parathyroidectomy in adults and children

\begin{tabular}{|c|c|c|c|c|}
\hline & \multicolumn{2}{|c|}{ Before parathyroidectomy } & \multicolumn{2}{|c|}{ After parathyroidectomy } \\
\hline & Adults & Children & Adults & Children \\
\hline Mean & 2.67 & 2.62 & 2.39 & 2.41 \\
\hline Standard deviation & 0.29 & 0.20 & 0.23 & 0.16 \\
\hline Median & 2.66 & 2.62 & 2.40 & 2.45 \\
\hline Maximum & 3.31 & 2.92 & 3.00 & 2.56 \\
\hline Minimum & 2.12 & 2.29 & 1.79 & 2.08 \\
\hline Missing & 21 & 0 & 19 & 0 \\
\hline $\mathrm{N}$ & 43 & 8 & 45 & 8 \\
\hline
\end{tabular}

Effect of parathyroidectomy on parathyroidhormone in adults

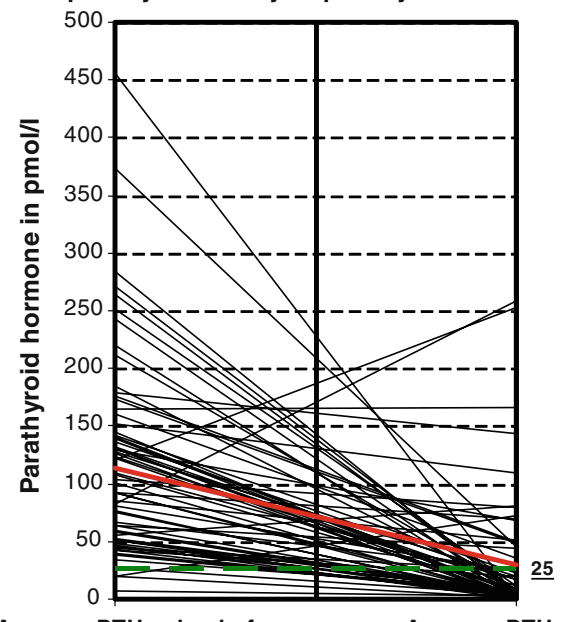

Average PTH value before Average PTH value after parathyroidectomy parathyroidectomy

Every line represents one adult patient, the red line represents the average.

Effect of parathyroidectomy on calcium levels in adults

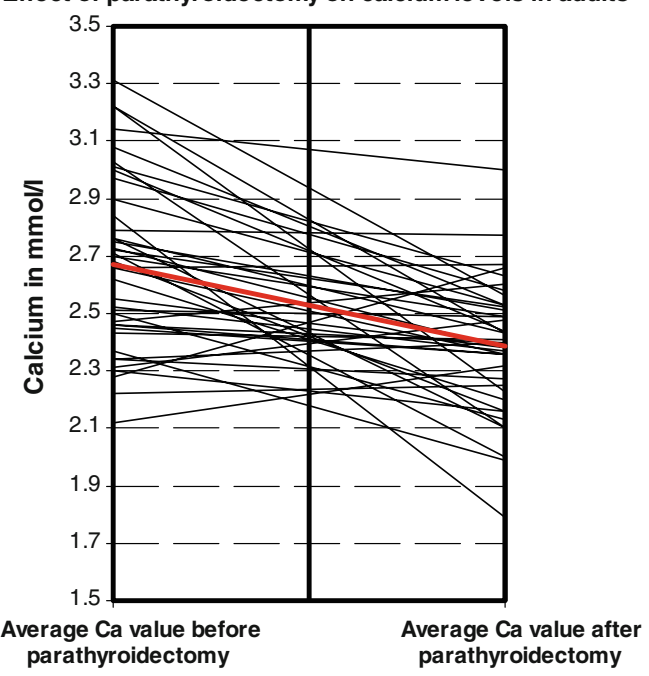

Every line represents one adult patient, the red line represents the average.

Fig. 1 Effect of parathyroidectomy on a parathyroidhormone, b calcium levels in adults
Effect of parathyroidectomy on parathyroidhormone in children

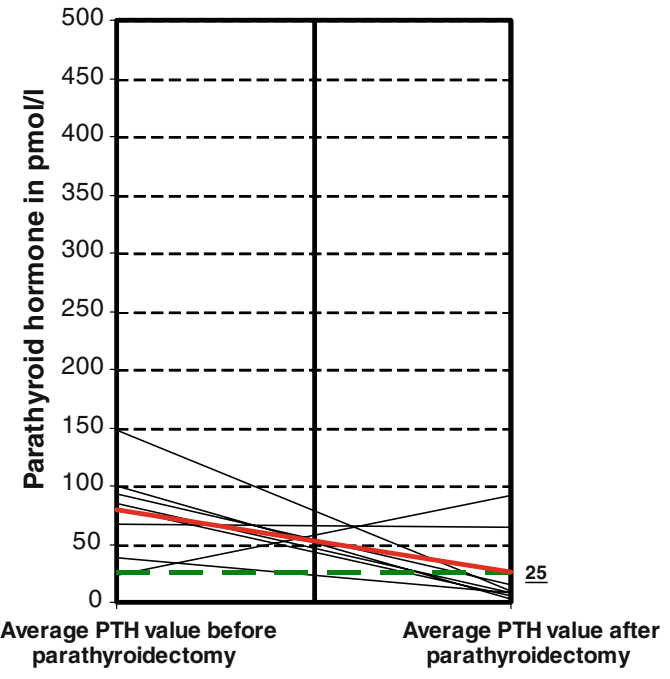

Every line represents one child patient, the red line represents the average.

Effect of parathyroidectomy on calcium levels in children

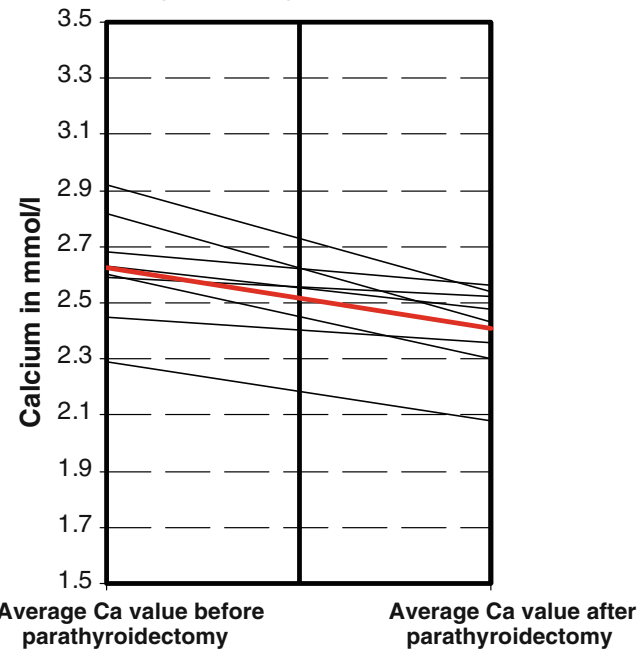

Every line represents one child patient, the red line represents the average.

Fig. 2 Effect of parathyroidectomy on a parathyroidhormone, b calcium levels in children 
values of less than $25 \mathrm{pmol} / \mathrm{l}$; in the other child, the PTH level normalized in the second year postoperatively.

Aparathyroidism

Seven patients, all adults, were considered to be aparathyroid. Six suffered from secondary hyperparathyroidism and one from tertiary hyperparathyroidism before operation.

Figure 3 gives a schematic illustration of the effectiveness of parathyroidectomy in the treatment of hyperparathyroidism.

Prevention of aparathyroidism by autotransplantation

Aparathyroidism was considered to have been prevented by autotransplantation in 54 patients, 7 children and 47 adults. These numbers includes some patients with parathyroid hormone levels $>25$ pmol/l. For 18 patients, 1 child and 17 adults, we were unable to confirm that autotransplantation did prevent aparathyroidism, as 7 had aparathyroidism and 11 had not had four glands removed. Fourteen patients, 1 child and 13 adults, had PTH values of $25 \mathrm{pmol} / \mathrm{l}$ or more after successful resection of four parathyroid glands and a forearm autograft. Therefore we considered the hyperfunction to be attributable to the autograft. Six patients, 1 child and 5 adults, had PTH values of $25 \mathrm{pmol} / 1$ or more after unsuccessful resection of four parathyroid glands and a forearm autograft. In these patients the cause for the continuing high PTH levels could either be the autotransplant or a gland that was not found.

\section{MIBI-scans}

In 4 of the 8 children treated, a MIBI-scan was performed. Three of these scans showed no activity in the arm and one did.

\section{Reoperations}

Persistent hypocalcemia required reoperation in 1 child and 4 adults. In the child, a fifth parathyroid gland was removed

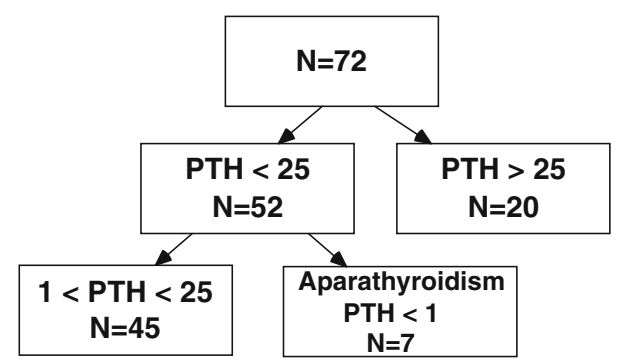

Fig. 3 Schematic illustration of effectiveness of parathyroidectomy for hyperparathyroidism from the left part of the thyroid gland. One adult had a fourth gland removed behind the corpus sterni, caudally from the vena anonima in the upper left mediastinum. One adult had a fifth gland removed, but its location was not described. One adult had a fifth gland removed from the upper right neck region. One adult had two reoperations: in the first, a fifth gland was found in the mediastinum and in the second the autotransplant was removed.

\section{Differences}

The values of the child and adolescent group $(n=8)$ were compared to the adult group $(n=64)$ with either the chisquare test or Fisher's exact test. No significant differences between the two groups in operative results were found.

\section{Discussion}

Because hyperparathyroidism is rare, children and adolescents as well as adults in the Netherlands are referred to a single specialized center for treatment. The Emma Children's Hospital AMC is an integrated pediatric hospital in the Amsterdam Medical Centre; both are specialized academic tertiary hospitals. To ensure high quality care, it is necessary to know whether it is possible to treat children and adolescents with renal hyperparathyroidism in the same way adults are treated for this disease.

The amount of information or evidence available was scarce; therefore this study was set up to investigate this matter. To research the outcome of parathyroidectomy it is necessary to be more specific than merely observing a decrease in PTH values and in symptoms, as reported in the 11 articles reviewed later. The National Kidney Foundation Kidney Disease Outcomes Quality Initiative was searched for guidelines and definitions for effectiveness of parathyroidectomy treatment, but none were found.

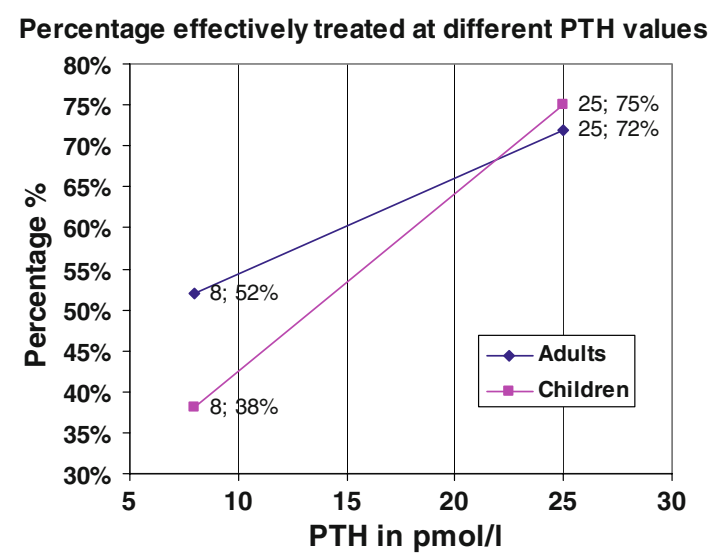

Fig. 4 Percentage effectively treated at different PTH values 
Fig. 5 Illustration of differences between adults and children in effectiveness of parathyroidectomy as treatment for hyperparathyroidism

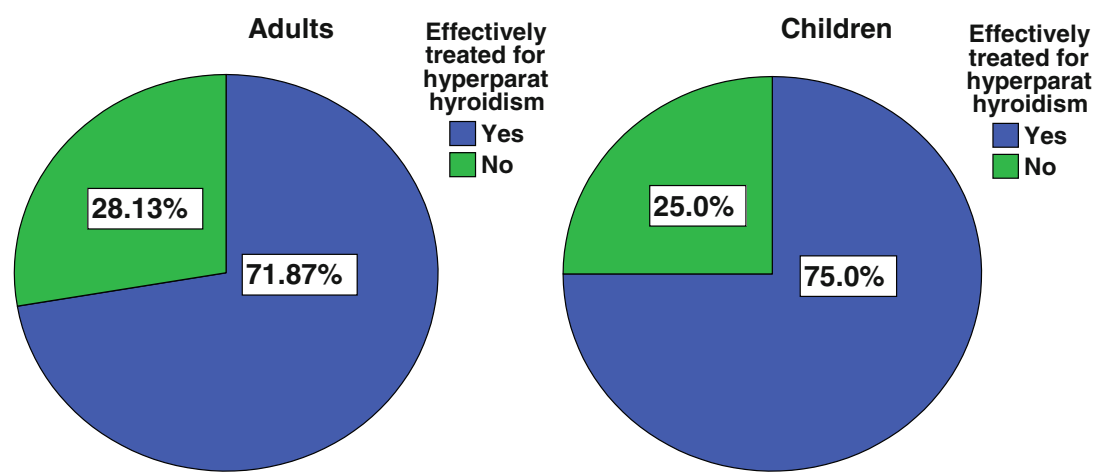

To provide a specific outcome evaluation, a PTH value that provided a realistic representation of effectively treated patients was needed. This was the value at which parathyroidectomy was found to be effective and reoperation was generally not considered. A PTH value of $8 \mathrm{pmol} / \mathrm{l}$ is generally considered normal. However, because of the variations in serum calcium that may result from dialysis, this is not a realistic value for most patients with renal failure who have undergone parathyroidectomy. As shown in Fig. 4, only $52 \%$ of adults and $38 \%$ of children would be considered effectively treated if a value of $8 \mathrm{pmol} / \mathrm{l}$ were upheld. This does not represent the effectiveness of treatment as patients with a value higher than $8 \mathrm{pmol} / \mathrm{l}$ but with a significant reduction of symptoms are still considered effectively treated. A PTH value of $25 \mathrm{pmol} / \mathrm{l}$ (three times the lower limit) or less gives a more realistic representation, with nearly three-quarters of patients effectively treated.

The choice of this value explains the difference in outcome between our group of patients and the patients described in the 11 articles reviewed later, as most of the latter patients did not have specific criteria as to what can be defined as effective treatment.

The results from our study give us reason to believe that parathyroidectomy is an effective treatment for hyperparathyroidism, in children as well as in adults. There were no significant differences between the children and adolescents and the adults in our study. Seven adult patients showed serum PTH values associated with aparathyroidism, 65 patients had no aparathyroidism. Aparathyroidism was not seen in the children and adolescent group.

In 54 patients we believe that autotransplantation prevented aparathyroidism, but in 14 of these patients we considered the autotransplant to have a hyper function. For 18 patients, 1 child and 17 adults, we were unable to confirm that it did, as 7 had aparathyroidism and 11 had not had four glands removed. No significant differences in effectiveness were seen between the two groups, as shown in Figs. 4 and 5.

We were not able to find any significant predictive factors for an effective surgical treatment, and therefore no comparison could be made between the two groups. In addition to our study, we performed a specific literature search on the operative treatment of secondary or tertiary hyperparathyroidism in children and adolescents. ${ }^{1}$ The PubMed search that was performed produced 125 articles, of which only 11 examined parathyroidectomy in children or adolescents with secondary or tertiary hyperparathyroidism. These 11 articles are summarized in Table 5.

As we wanted to know if parathyroidectomy is an effective treatment for secondary and tertiary hyperparathyroidism in children and adolescents, we searched these 11 articles for effective and ineffective outcome findings. Generally, an outcome was considered to be effective if the symptoms of hyperparathyroidism-related bone disease and PTH values were reduced. Ten of the 11 articles reported effective outcome results in 35 of 36 patients treated. In one article, only the abstract was traceable and it contained no information on the type of operation or effectiveness.

Combining the facts from the other 11 articles and our own study, we came to the conclusion that total parathyroidectomy and forearm autograft is as effective a treatment for secondary and tertiary hyperparathyroidism in children and adolescents as it is in adults. We believe our findings justify treating children and adolescents the same way as adults.

\footnotetext{
1 The search terms were as follows: (("Hyperparathyroidism, Secondary/surgery" $[\mathrm{MeSH}] \quad$ OR ("Hyperparathyroidism/surgery" $[\mathrm{MeSH}]$ AND (("secondary" [Subheading] OR secondary[Text Word]) OR tertiary[All Fields]))) OR (("hyperparathyroidism"[MeSH Terms] OR hyperparathyroidism[Text Word]) AND (("secondary"[Subheading] OR secondary[Text Word]) OR tertiary[All Fields]) AND ("Parathyroidectomy"[MeSH] OR ("surgery"[Subheading] OR “operative surgical procedures"[Text Word] OR "surgical procedures, operative"[MeSH Terms] OR "surgery"[MeSH Terms] OR surgery[Text Word]) OR ("parathyroidectomy" [MeSH Terms] OR parathyroidectomy[Text Word])))) AND (pediatric[All Fields] OR "child"[MeSH Terms] OR child[Text Word] OR ("child"[TIAB] NOT Medline[SB]) OR "child"[MeSH Terms] OR children[Text Word] OR "adolescent" [MeSH Terms] OR adolescent[Text Word]) AND hyperparathyroidism[TI] AND hasabstract[text].
} 
Table 5 Literature overview of parathyroidectomies performed on children suffering from secondary or tertiary hyperparathyroidism

\begin{tabular}{lllll}
\hline Author & Year & Journal & N & Type of parathyroidectomy \\
\hline Rothmund et al. [12] & 1976 & Dtsch Med Wochenschr 101:1669-1667 & 1 & $\begin{array}{c}\text { Total + autotransplantation } \\
\text { treated }\end{array}$ \\
Moazam et al. [13] & 1984 & J Pediatr Surg 19:389-393 & 2 & Total + autotransplantation \\
Alon et al. [14] & 1984 & Int J Pediatr Nephrol 5:39-43 & 1 & Total \\
Rivkees et al. [15] & 1992 & J Clin Endocrinol Metab & 3 & $n=2$ : total + autotransplantation. \\
& & 75:1514-1518 & & n = 1: 3 glands found $>$ no \\
Ozen et al. [16] & 1994 & Int Urol Nephrol 26:481-484 & & autotransplant \\
Zachariou et al. [17] & 1995 & Eur J Pediatr Surg 5:288-291 & 1 & Total + autotransplantation \\
Zouboulis et al. [18] & 1996 & Br J Dermatol 135:617-622 & 1 & Unknown \\
Nieto et al. [19] & 1997 & Pediatr Nephrol; 11(1):65-68 & 1 & Total \\
Martinez et al. [20] & 1997 & Cir Pediatr 10:13-17 & 2 & Subtotal \\
Jobs et al. [21] & 2003 & Pol Merkur Lekarski 14):450-452 & 2 & Total + autotransplantation \\
Schlosser et al. [22] & 2008 & World J Surg 32:801-806 & 21 & Subtotal \\
Total & & & 36 & Total + autotransplantation \\
\hline
\end{tabular}

Open Access This article is distributed under the terms of the Creative Commons Attribution Noncommercial License which permits any noncommercial use, distribution, and reproduction in any medium, provided the original author(s) and source are credited.

\section{References}

1. Haberal M, Cuhadaroglu S, Velidedeoglu E et al (1994) Pediatric kidney transplantation. Transplant Proc 26:185-186

2. Postlethwaitè RJ (1986) Clinical paediatric nephrology. IOP Publishing Limited, Bristol, UK

3. Dotzenrath C, Cupisti K, Goretzki E et al (2003) Operative treatment of renal autonomous hyperparathyroidism: cause of persistent or recurrent disease in 304 patients. Langenbecks Arch Surg 387:348-354

4. Jofre R, Lopez Gomez JM, Menarguez J et al (2003) Parathyroidectomy: whom and when? Kidney Int 85(Suppl):S97-S100

5. Conzo G, Celsi S, Buffardi R et al (2002) Total parathyroidectomy with or without autoimplantion in the therapy of secondary hyperparathyroidism. Minerva Chir 57:309-315

6. Tominaga Y, Matsuoka S, Sato T (2005) Surgical indications and procedures of parathyroidectomy in patients with chronic kidney disease. Ther Apher Dial 9:44-47

7. Malmaeus J (1983) Secondary hyperparathyroidism in chronic renal failure. Scand J Urol Nephrol 70(Suppl):S1-S63

8. Tominaga Y, Uchida K, Haba T et al (2001) More than 1,000 cases of total parathyroidectomy with forearm autograft for renal hyperparathyroidism. Am J Kidney Dis 38(4 Suppl 1):S168-S171

9. Ross AJ III (1991) Parathyroid surgery in children. Prog Pediatr Surg 26:48-59

10. Talwalkar YB, Puri HC, Hawker CC et al (1979) Parathyroid autotransplantation in renal osteodystrophy. Am J Dis Child 133:901-905

11. Klaus G, Watson A, Edefonti A et al (2006) Prevention and treatment of renal osteodystrophy in children on chronic renal failure: European guidelines. Pediatr Nephrol 21:151-159

12. Rothmund M, Kohler H, Dieker P et al (1976) Total parathyroidectomy and autologous parathyroid transplantation in secondary hyperparathyroidism (author's transl). Dtsch Med Wochenschr 101:1667-1669

13. Moazam F, Orak JK, Fennell RS III et al (1984) Total parathyroidectomy and autotransplantation for tertiary hyperparathyroidism in children with chronic renal failure. J Pediatr Surg 19:389-393

14. Alon U, Newsome H Jr, Chan JC (1984) Hyperparathyroidism in patients with X-linked dominant hypophosphatemic ricketsapplication of the calcium infusion test as an indicator for parathyroidectomy. Int J Pediatr Nephrol 5:39-43

15. Rivkees SA, el-Hajj-Fuleihan G, Brown EM et al (1992) Tertiary hyperparathyroidism during high phosphate therapy of familial hypophosphatemic rickets. J Clin Endocrinol Metab 75:15141518

16. Ozen S, Saatci U, Sayek I et al (1994) Brown tumour as a complication of secondary hyperparathyroidism in uraemia: a case report. Int Urol Nephrol 26:481-484

17. Zachariou Z, Buhr H, von Herbay A et al (1995) Preoperative diagnostics and surgical management of tertiary hyperparathyroidism after chronic renal failure in a child. Eur J Pediatr Surg $5: 288-291$

18. Zouboulis CC, Blume-Peytavi U, Lennert T et al (1996) Fulminant metastatic calcinosis with cutaneous necrosis in a child with end-stage renal disease and tertiary hyperparathyroidism. Br J Dermatol 135:617-622

19. Nieto J, Ruiz-Cuevas P, Escuder A et al (1997) Tertiary hyperparathyroidism after renal transplantation. Pediatr Nephrol 11:65-68

20. Martinez L, Alonso A, Meseguer MC et al (1997) Surgical treatment of tertiary hyperparathyroidism in childhood. Cir Pediatr 10:13-17

21. Jobs K, Boguszewska-Baczkowska A, Rubik J et al (2003) Atypical osteitis in hemodialysed child with uncontrolled secondary hyperparathyroidism: a case report. Pol Merkur Lekarski $14: 450-452$

22. Schlosser K, Schmitt CP, Bartholomaeus JE et al (2008) Parathyroidectomy for renal hyperparathyroidism in children and adolescents. World J Surg 32:801-806 